This document is a manuscript version of the following article:

Title: Customer segmentation revisited: The case of the airline industry

By: Teichert, Thorsten; Shehu, Edlira; von Wartburg, Iwan

Published in: Transportation Research Part A: Policy and Practice

Volume 42, Issue 1, January 2008, Pages 227-242

Publisher: Elsevier | Year: 2008

DOI: 10.1016/j.tra.2007.08.003

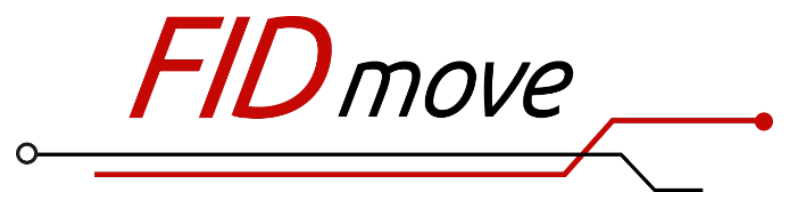

Brought to you by the Scientific Information Service for Mobility and Transport Research

Fachinformationsdienst Mobilitäts- und Verkehrsforschung

Website: www.fid-move.de

Repository: publish.fid-move.de

Contact: publish@fid-move.de

(C) 2008. This manuscript version is made available under the CC-BYNC-ND 4.0 license.

http://creativecommons.org/licenses/by-nc-nd/4.0/ 


\title{
Customer Segmentation Revisited: The Case of the Airline Industry
}

\author{
Prof. Dr. Thorsten Teichert ${ }^{\bowtie}$ \\ University of Hamburg, Chair of Marketing and Innovation, Von-Melle-Park 5, D- \\ 20146 Hamburg, Germany, Phone: +49 (040) 42838 4643, Fax: +49 (040) 428385250 , \\ teichert@econ.uni-hamburg.de
}

Edlira Shehu

University of Hamburg, Chair of Marketing and Innovation, Von-Melle-Park 5, D20146 Hamburg, Germany, shehu@econ.uni-hamburg.de

Iwan von Wartburg

University of Hamburg, Chair of Marketing and Innovation, Von-Melle-Park 5, D20146 Hamburg, Germany, wartburg@econ.uni-hamburg.de 


\section{Abstract}

Although the application of segmentation is a topic of central importance in marketing literature and practice, managers tend to rely on intuition and on traditional segmentation techniques based on socio-demographic variables. In the airline industry, it is regarded as common sense to separate between business and economy passengers. However, the simplicity of this segmentation logic no longer matches the ever more complex and heterogeneous choices made by customers. Airline companies relying solely on flight class as the segmentation criterion may not be able to customize their product offerings and marketing policies to an appropriate degree in order to respond to the shifting importance and growing complexity of customer choice drivers, e.g. flexibility and price as a result of liberalization in the airline industry. Thus, there is a need to re-evaluate the traditional market segmentation criterion.

By analyzing the stated preference data of more than 5800 airline passengers, we show that segmenting into business and leisure (a) does not sufficiently capture the preference heterogeneity among customers and (b) leads to a misunderstanding of consumer preferences. We apply latent class modeling to our data and propose an alternative segmentation approach: we profile the identified segments along behavioral and sociodemographic variables. We combine our findings with observable consumer characteristics to derive pronounced fencing mechanisms for isolating and addressing customer segments receptive for tailored product packages.

Key Words: Airline Industry, Segmentation, Preference Heterogeneity, Latent Class 


\section{$1 \quad$ Introduction}

The airline industry is currently undergoing one of the major transitions in its history (Doganis, 2006: 8-12). Landmark changes in the market environment have led to ever stronger competition in the airline industry (Alamdari and Mason, 2006, Mason, 2005). Low cost carriers (LCC) have entered the market and established themselves by penetrating significant parts of the markets. This already led to dramatic changes in the competitive landscape. While the industry used to be regulated and dominated by governmental players, now it is shaped by competitive offensives of companies. In this new setting, the need becomes prevalent for a market-oriented approach to product optimization. Traditionally, airlines segment their customers into business and economy passengers and align their product strategy with flexibility for business passengers and price for economy passengers. The highly competitive situation and the higher market transparency have induced a change in market power constellations in favor of the customers who are now becoming more conscious of their needs. Furthermore, the Internet as an information and distribution channel with minor information and transaction costs intensifies these changes in customers' preferences and their behavior (Alamdari and Mason, 2006, Lindstadt and Fauser, 2004).

As market and buying behaviors of customers change it is important to assess the nature of their behavior in the future. The impact of behavior-related latent constructs, such as attitudes and personality traits on mode choice has been investigated before (Anable and Gatersleben, 2005, Johansson et al., 2006). We contribute to the discussion by investigating intra-modal choices as a basis for identifying customer preferences. Here, segmentation concepts become more relevant for understanding customers, for the 
allocation of resources and adaptation of product mixes, as well as for the development of new product-/market approaches (Palmer and Millier, 2004). Therefore, effective customer segmentation is crucial for a sustainable product strategy: managers of network carriers must know whether their products, hitherto tailored to business and economy passengers, need to be redesigned in response to an increased heterogeneity in customers' preferences. The inappropriateness of the traditional segmentation approach to come to grips with stronger heterogeneity has already been indicated by previous studies (Mason, 2003, Mason, 2002).

Such a need for addressing customer preferences can even be identified for low-cost carriers. Managers of these carriers need current information about preferences in different customer segments in order to be able to target these segments more effectively when it comes to bundling product and service offerings that complement the standardized flight product. Such measures may help the carriers to overcome a dubious trend towards commodification of air travel and - thus - to foster customer retention for ensuring long-term profitability.

This paper addresses the appropriateness of flown class as the predominant segmentation criterion in the airline industry. We expect this logic to lead to product offerings which do not fulfill the specific needs of customers, as preference heterogeneity within both business and economy-class segments remains unconsidered. We derive propositions (section 2) which we test in our empirical study (section 3) by applying latent class modeling (section 4) to stated preference data from a choice-based conjoint survey of more than 5800 passengers. Our latent class analysis provides customer segments with homogeneous preferences. We discuss attitudinal and socio-demographic segment-based profiles using observable variables in section 5. This allows us to identify operable 
customer segments which can be addressed effectively by product managers to develop fencing mechanisms which may serve as an important marketing management instrument. To conclude, we offer implications both for management as well as for public policy and an outlook for further research in section 6 .

\section{Contextual and Conceptual Background}

\subsection{Business environment in the airline industry}

While, in the past, the airline industry was characterized both by high growth rates and governmentally regulated protectionism, the liberalization of the airline industry in the EU has lead to the development of a highly competitive market (Doganis, 2006:10). The most obvious evidence for increasing competition is the market entrance of Low Cost Carriers who touted generally a simplified fare structure with lower ticket prices capturing thus significant market shares of ca. $10 \%$ in Europe and $20 \%$ in North America. According to Doganis (2006: 22) Ryanair and easyJet, the dominant LCCs in Europe, grew their passenger traffic at an average rate of over $40 \%$ p.a. between 2000 and 2004 . Many network carriers, such as British Airways, were failing to operate profitably. While the LCC initially targeted the leisure segment, there is evidence of an increasing number of business travelers flying with these airlines. Several studies indicate that the traffic mix of economy, business and first class passengers has changed over the last 10 years. Under these circumstances, knowing customer preferences and predicting their choice decisions becomes an ever more important consideration for the marketing policies of airline companies. 
The highly competitive environment leads to customer behavioral changes. In the past, the airline industry has relied on a combination of high-paying business travelers and price-sensitive economy passengers. Since the "old days", the proportion of economy passengers has risen, while the average fare of these passengers has fallen by a third (Swan, 2002). Business passengers are tending to choose tickets based on prices. A survey of short-haul business passengers found $40 \%$ of this market to be price elastic and to make extensive use of LCC tickets (Mason, 2002). The market changes have had an impact on leisure travelers' behavior as well. The market entry of LCCs has added new segments of price-sensitive passengers to the market, causing an increase of the popularity of "short breaks" in the last few years. The number of holiday packages is decreasing because LCCs offer leisure travelers the possibility of traveling at more attractive times or more flexibly and of organizing their holidays by themselves (Mason, 2005). In the upperechelon of the market, jet sharing companies offering expensive but efficient and reliable connections between economically important cities have made pathway into the senior manager market.

These effects were amplified by the establishment of Internet as a new distribution channel. The rise of Internet tore down the barriers of the availability of competitive ticket price information. Distribution costs also decreased due to the lower number of intermediary agents in the transaction processes. Thanks to lower search and transaction costs, customers can directly influence the price because they can access the fares of dozens of airlines, for any destination, with route and time of departure. .

In spite of these drastic market as well as demand changes, network carriers based their marketing activities on a two-class customer segmentation in business and leisure travelers. Business travelers were assigned to fully refundable tickets, leisure travelers to 
low priced tickets. Today, proportionally more travelers than in the past choose economyclass products (Mason, 2005). Increasing price sensitivity has led to reduced average yields of airlines and to excess capacities in the market. These factors intensified competition and in turn were amplified by external market shocks such as higher kerosene costs and economic shifts in western European countries (Inglanda et al., 2006).

Due to a lack of focus in product policy, network carriers and LCC often aim to reach the same consumer segments. Network carriers were hence obliged to revise their business model by adapting to the low-pricing strategies of LCCs which obtained a significant cost advantage. However, the cost-reducing measures of network carriers are ineffective for handling the needs of both traditionally differentiated segments. As a consequence, business customers buy products that do not satisfy their quality expectations and leisure travelers receive over-engineered offerings that surpass their quality expectations, but not fulfill their price expectations (Lindstadt and Fauser, 2004). This is likely to lead to further erosion of market share on both sides. Given the inherent cost structure of network carriers, they should strive to better serve those customers who are not focusing on price alone but who seek tailored product offerings. Our hypothesis is that these customers are ill served and that they are in demand for new product offerings which combine utilitarian as well as hedonic features.

In sum, airline companies are faced both with major changes in their business environment and the changes in customer behavior. The class flown seems to be no longer an appropriate indicator for identifying discriminately heterogeneous customer segments. Traditional segmentation of passengers in business and leisure is becoming obsolete because preference spectra within both classes are becoming wider (Alamdari and Mason, 2006). New segmentation techniques are needed for identifying different segments which 
represent homogeneous customer preferences and which are responsive to targeted product offerings. In the next section we present a brief definition and a review of segmentation methods. Following this, we will apply a new way of segmentation to an especially important market population: the frequent flyers of a network carrier.

\subsection{Market Segmentation Techniques}

The importance of segmentation for marketing strategies is widely acknowledged (Wedel and Kamakura, 2000). Segmentation, essentially from both a marketing practice and a research perspective, is simply the act of defining meaningful sub-groups of individuals or objects (Haaijer et al., 1998). At its core, it is about reducing the number of entities being dealt with into a manageable number of groups that are mutually exclusive and share well defined characteristics (Yankelovich and Meer, 2006). Once identified, it is possible to make predictions about the groups' responses to various situations, to align marketing strategies and types of policy, and to allow more creative and better-targeted policies to emerge. Although the intent of segmentation remains largely undisputed, in reality, the term 'segmentation' encompasses a broad variety of approaches (see Wedel and Kamakura 2000 for a review). Essentially, these approaches can be split into (i) a priori approaches, i.e. based on known characteristics, groups are selected from a population in advance and declared as 'segments' (e.g. sociodemographic characteristics or frequency of car use) and (ii) post hoc approaches, i.e. empirical investigation is conducted using multivariate analysis to identify segments (Anable, 2005). In post hoc approaches, respondents are clustered according to their 
similarity on multivariate profiles on any number of combinations of variables. These may include various mixtures of, e.g. attitudinal, behavioral or personality characteristics.

More recently, post hoc segmentation methods based on latent variables are being used; these methods make inferences about brand preference and attribute importance (Kamakura and Russell, 1989, Wedel and Kamakura, 2000). These models rest on the central assumption of discrete distribution of preferences in a sample. They simultaneously estimate segments and segment-based part- worths in a given sample. The approach has the advantage of deriving segments that are more directly linked to actual marketplace preferences and behaviors (Allenby et al., 2002). A variety of latent class applications have been conducted during the last years focusing on the predictive and estimation power of this approach (Abramson et al., 2000, Kim et al., 2002, Vermunt and Magidson, 2003, Wedel and Kamakura, 2000). We contribute to this discussion by applying latent class modeling to a large sample of customers in an application context characterized by a strong need for new segmentation techniques, i.e. the airline industry.

\section{Empirical Study}

\subsection{Empirical Field and Data Gathering}

Our data to explore are stated preferences data. Stated preference surveys are frequently adopted for the analysis of the travel demand (Hensher, 1994, Louviere, 1988). Respondents are asked to state their preferences in fictitious choice situations. Using the data, a utility function is estimated and purchasing behavior is forecasted using these estimated parameters. 
Stated preferences enable investigation of new product features or combinations of features which do not yet exist in the market (Hensher et al., 1999). Thus, stated preferences are an extremely reliable and early indicator of changing consumer preferences, allowing airline companies to implement proactive product policies. For our purposes, an analysis of revealed preferences would not be as beneficial, as this would only tell us about the status quo of consumer behavior in existing product-/market environments. The link between preferences stated in the survey and those articulated in actual market choices is well researched both conceptually (Morikawa, 1989) and statistically (Swait and Louviere, 1993). Furthermore, this deduction has been tested in numerous empirical studies in different fields of research, such as marketing, transport and tourism (Louviere et al., 2000, Louviere, 2001).

Our sample consists of frequent-flyer passengers (FFP) of an international long- and short-haul airline who traveled on at least one of eleven selected European short-haul routes. Frequent-flyer passengers of the analyzed airline used to be "heavy-user" consumers with very high customer loyalty only. For this reason FFP are an especially important segment for the airlines. Accordingly, the FFP program is given major managerial attention in the analyzed airline. Usually, and this is also holds for the conventional wisdom in the analyzed airline, frequent flyers are believed to consist of non-price-sensitive business-class passengers buying expensive tickets with high degree of flexibility (Mason, 2005). However, since the European market for the analyzed airline has become much more competitive and, as a consequence, the average number of FFP memberships per frequent passenger has risen, there is reason to believe that the once believed match between FFP and business passengers is at least partly diluted. Thus, by 
analyzing the preferences of this target group, we are able to derive relevant implications for future product strategy.

The data were collected by means of a choice-based conjoint survey. The experimental design consists of seven attributes with two levels for each attribute (Table 1). The selection of relevant attributes bases on a meta-analysis of on-board and off-board surveys on relevant product features for air-travel demand. The results of the meta-analysis were evaluated stepwise by eliminating product attributes which are irrelevant for the scope of our study (e.g. comfort-related attributes for long-haul flights). Product features which cannot be modified by airline management in the short term were also omitted. The attributes were evaluated in a final step, using a scoring model as well as expert interviews.

Table 1: Relevant product attributes

\begin{tabular}{|c|c|c|c|}
\hline Feature & Definition & First Level & Second Level \\
\hline Flight Schedule & $\begin{array}{l}\text { Frequency with which one } \\
\text { can travel between two } \\
\text { destinations }\end{array}$ & $\begin{array}{l}\text { At least twice a day in } \\
\text { every direction }\end{array}$ & Once a day \\
\hline Total Fare & One way flight fare & $\begin{array}{l}\text { „Regular IATA Tariff“ (> } \\
200 €)\end{array}$ & $\begin{array}{l}\text { "Discount Tariff" } \\
(100 €)\end{array}$ \\
\hline Flexibility & $\begin{array}{l}\text { Ease and flexibility of } \\
\text { travel plan and booking } \\
\text { changes, }\end{array}$ & $\begin{array}{l}\text { Changes can be made } \\
\text { without restrictions }\end{array}$ & $\begin{array}{l}\text { Changes can only be } \\
\text { made causing severe } \\
\text { restrictions }\end{array}$ \\
\hline Frequent Flyer Program & $\begin{array}{l}\text { Possibility to collect miles } \\
\text { or bonus points }\end{array}$ & $\begin{array}{l}\text { FFP existing from which I } \\
\text { can profit }\end{array}$ & $\begin{array}{l}\text { FFP existing from which I } \\
\text { cannot profit }\end{array}$ \\
\hline Punctuality & $\begin{array}{l}\text { Dependability to be on } \\
\text { time most often and } \\
\text { therefore to posses } \\
\text { security of planning the } \\
\text { schedule }\end{array}$ & $\begin{array}{l}\text { Punctual almost every } \\
\text { time }\end{array}$ & $\begin{array}{l}\text { Delayed for about } 30 \\
\text { minutes many times }\end{array}$ \\
\hline Catering & $\begin{array}{l}\text { Basic food and beverage } \\
\text { in-flight services }\end{array}$ & Included in ticket fare & $\begin{array}{l}\text { Can be bought during } \\
\text { flight }\end{array}$ \\
\hline Ground Services & $\begin{array}{l}\text { Additional services on } \\
\text { ground (e.g. quick check- } \\
\text { in) }\end{array}$ & $\begin{array}{l}\text { Time-saving services on } \\
\text { ground can be used on } \\
\text { ground }\end{array}$ & $\begin{array}{l}\text { No time-saving services } \\
\text { can be used on ground }\end{array}$ \\
\hline
\end{tabular}


A full factorial design containing 128 scenarios $\left(2^{7}\right)$ was generated. This allows estimation of both main effects as well as interaction effects without biases. Each choice scenario contained full profile descriptions of two flight alternatives. All respondents were asked to evaluate eight different choice tasks drawn randomly. Besides the choice tasks, the questionnaire contained two further question blocks concerning customer attitudes, flight behavior as well as socio-demographics.

We received responses from 6.842 FFP members. This amounts to a response rate of around $25 \%$, which is higher than the participation rate in other surveys of the airline. After excluding observations with missing values, we derived our final data set composed of 5.829 respondents. Business-class and economy-class passengers represent $88 \%$ and $12 \%$ of the sample, respectively. The sample's composition deserves some discussion. First, a high proportion of business-class customers demonstrates the relevancy of our analyses for airlines companies seeking to retain these especially attractive key customers. Second, it is an indicator for erosion effects caused by increasing price sensitivity of passengers as discussed in chapter 2.2. Under traditional premises, we would have expected an even more overwhelming percentage of business-class customers in the FFP-population of this high-class airline.

\subsection{A Priori Segmentation}

Based on the discrete choice theory, we estimate the data with a multinomial logit model (McFadden 1974, Train, 2003). In a first step, we determine the optimal model specification by stepwise testing for significant interactions and excluding insignificant ones. The optimal model specification consists of seven main effects and two interaction 
effects between schedule and price and catering and price. We make use of class flown as an a priori segmentation criterion and estimate separate logit models for the business and the economy-class segment (Table 2).

Table 2: Estimation of logit models for business and economy passengers

\begin{tabular}{|l|l|l|l|l|l|}
\hline \hline & \multicolumn{2}{|c|}{ Business } & \multicolumn{2}{c|}{ Economy } & Total \\
\hline & Parameters & $t$-values & Parameters & t-values & Paired t-test \\
\hline SCHEDULE & 0,44 & 58,90 & 0,45 & 21,36 & $-10,19$ \\
\hline PRICE & $-0,75$ & $-73,17$ & $-0,26$ & $-14,62$ & $-714,59$ \\
\hline FLEXIBILITY & 0,39 & 63,66 & 0,53 & 24,57 & $-175,42$ \\
\hline FFLYER & 0,40 & 62,68 & 0,42 & 21,73 & $-16,04$ \\
\hline PUNCTUALITY & 0,59 & 68,29 & 0,60 & 32,00 & $-15,64$ \\
\hline CATERING & 0,17 & 25,79 & 0,26 & 14,62 & $-125,18$ \\
\hline GROUND & 0,12 & 18,71 & 0,11 & 5,38 & 13,48 \\
\hline SCHEDULE*PRICE & $-0,02$ & $-2,20$ & $-0,02$ & $-1,06$ & 5,11 \\
\hline CATERING* PRICE & 0,02 & 3,18 & $-0,01$ & $-0,81$ & 50,28 \\
\hline CONST & 0,05 & 3,87 & $-0,01$ & $-0,30$ & 47,41 \\
\hline LL & $-19874,67$ & & $-2829,86$ & & \\
\hline P & 0,29 & & 0,25 & & \\
\hline BIC & 39855,40 & & 5745,78 & & \\
\hline CAIC & 39855,40 & & 5745,78 & & \\
\hline Number of respondents & 5133 & & 696 & & \\
\hline \hline
\end{tabular}

The segments do not show the preferences one might intuitively expect, i.e. that economy passengers are more price-sensitive but less sensitive to schedule, punctuality, and flexibility. In contrary, economy passengers are even less price-sensitive than business passengers. Both segments place major emphasis on punctuality. Flexibility is important for business-class passengers, but also has a strong impact on choice decisions of economy passengers. While schedule is relevant for both segments, ground services 
are not appreciated by both classes. In sum, we observe fewer preference differences between the two segments than conventional wisdom would lead us to expect.

A possible explanation for the counterintuitive findings is that we rely exclusively on data from frequent flyers. These high-affinity individuals are likely to have well-established and generic or shared preference patterns due to their intensive product experiences. Thus, a certain degree of utility coherence seems reasonable. It may well be the case that external conditions, e.g. company-specific regulations or travel policies for class flown, can be held accountable for the persons belonging to either the business- or the economyclass traveller segment. Thus we expect similar basic preference trade-offs, e.g. between price and comfort-related features. On the other hand, using class flown as the only segmentation criterion does not allow for individual-specific utility differences, which are caused by various personal and/or behavioral characteristics. Thus, preference heterogeneity is likely to be found both across and within the two segments.

This has methodological implications as the logit model tries to find the "most likely" parameter for the whole data set. The smaller the in-group variance of a utility estimator, the more the estimate stands out in comparison to the others. The estimators get stuck in the middle in cases of sub-segments with highly deviating preferences. Our findings can be interpreted in view of this methodological phenomenon: The especially high partworth values for punctuality indicate an overall agreement with respect to the relative importance of this attribute. On the contrary, the astonishingly low significance of the price estimator within the economy-class segment suggests high deviations in the valuation of price. Thus we infer that considerable preference heterogeneity within each class remains unexplained. 
The counterintuitive results of the first analysis of preferences based on the traditional business/economy dichotomy led us to test the degree of homogeneity within both segments. For this we built two sub-groups within the business and economy segments according to the a priori criterion of travel reason. Respondents specified their reason for air travel before making the eight choices between two fictitious flight alternative choicesets. Thus, according to Figure 1, each segment is divided into two sub-segments, i.e. passengers flying for business or for leisure.

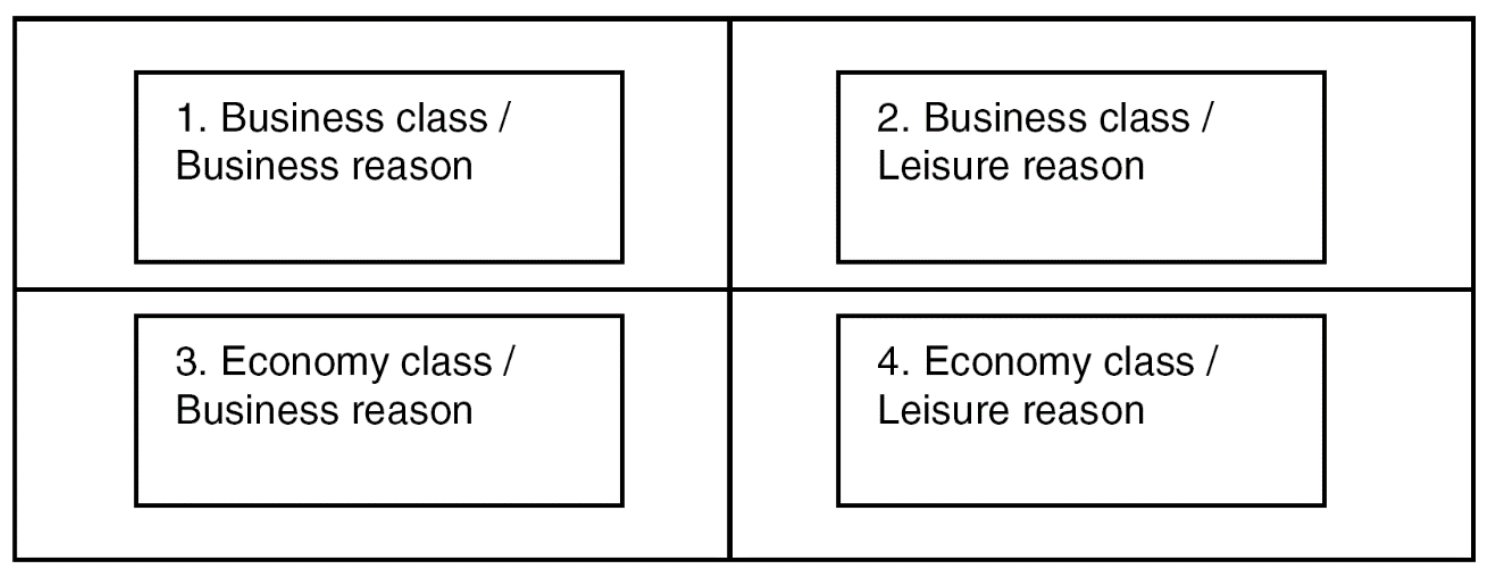

Fig. 1. A priori classification.

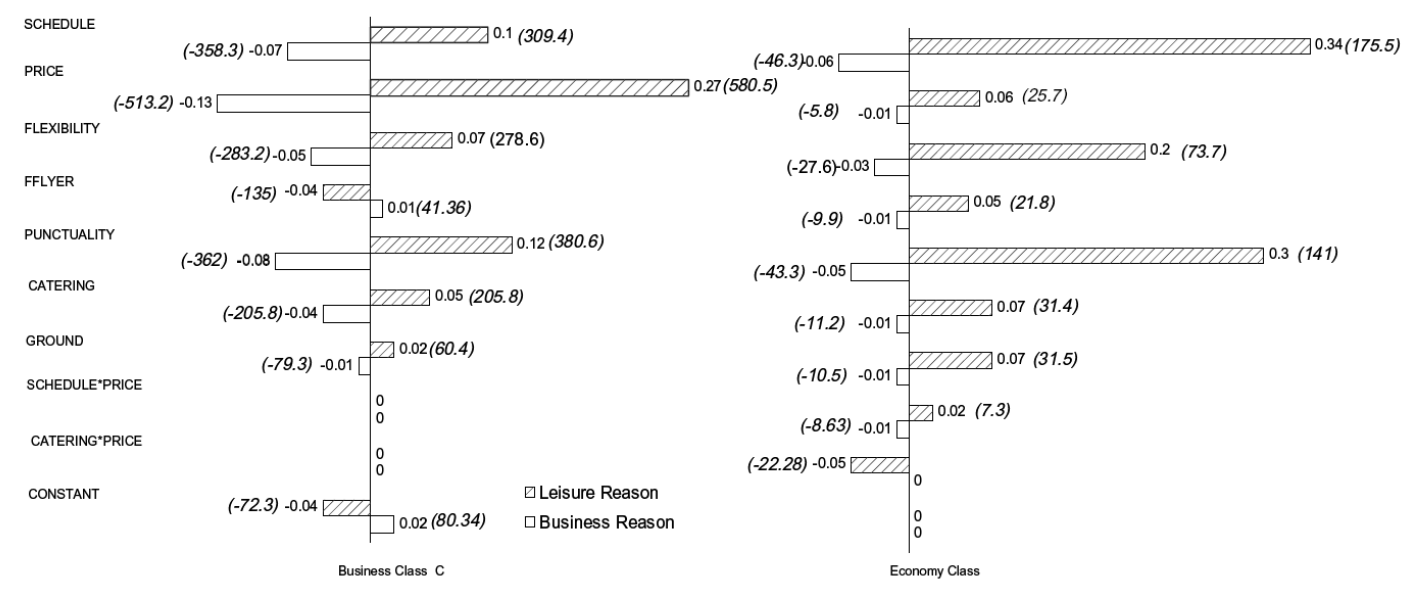

Fig. 2. Relative deviations of parameter estimates ( $t$-values in parentheses). 
The traditional segmentation strategy of airlines according to class flown implies that business travelers mostly fly business class and leisure travelers mostly fly economy class. Contrary to this expectation, we observe that class flown does not necessarily correspond to travel reason. Thus, instead of two classes as expected, we identify four customer segments. In order to test for homogeneity, separate logit estimations are conducted for each sub-class. The results support our hypotheses of deviating preference patterns within the segments. Figure 2 shows the relative deviations of sub-group preference estimates from either business- or economy-class segment estimate. If class flown was sufficient for segmentation, leisure versus business reason should not matter. Paired t-tests show significant parameter differences, however. This supports our hypothesized result concerning the inefficiency of the simple segmentation in businessand economy-class passengers.

Two main preference patterns emerge from the analysis. First, business-class travelers flying for a business reason have significantly higher partworths for comfort-related features than when they fly for leisure reasons. Second, they are less price-sensitive when traveling for business than for leisure reasons. For economy travelers the same pattern holds. These customers attach more value to comfort-related variables and less to price, when they fly on business, compared to when they travel for leisure reasons. These systematic deviations clearly indicate the inefficiency of class flown as the sole segmentation criterion for representing customer preferences and capturing heterogeneity. 


\section{A Latent-Class Approach to Market Segmentation}

Unlike most of the ad-hoc clustering methods which merely present convenient heuristics for deriving segments in a sample, latent class models allow for segment-based estimation within the framework of standard statistical theory (Wedel and Kamakura, 2000:101). The fundamental assumption underlying LC models is that of local independence which states that objects of the same segment share a common joint probability distribution among the observed variables, enabling thus the simultaneous identification of classes and description of the within-class structure of the observations (Vermunt and Magidson, 2003). The solution with the highest fit for the data is determined by means of different information criteria. Comparing the Bayesian Information Criterion (BIC) shows that the best solution consists of a five customer segment solution. 
Table 3: Partworths of the 5-segment solution

\begin{tabular}{|c|c|c|c|c|c|c|c|c|c|c|}
\hline & \multicolumn{2}{|c|}{$\begin{array}{l}\text { Seg. 1: } \\
\text { Efficiency/Punctuality }\end{array}$} & \multicolumn{2}{|c|}{$\begin{array}{l}\text { Seg. 2: } \\
\text { Comfort }\end{array}$} & \multicolumn{2}{|c|}{$\begin{array}{l}\text { Seg. 3: } \\
\text { Price }\end{array}$} & \multicolumn{2}{|c|}{$\begin{array}{l}\text { Seg. } \\
4 \text { Price/Performance }\end{array}$} & \multicolumn{2}{|c|}{$\begin{array}{l}\text { Seg. 5: } \\
\text { Catch all/Flexibility }\end{array}$} \\
\hline & $\beta$ & t-values & $\beta$ & t-values & $\beta$ & t-values & $\beta$ & t-values & $\beta$ & t t t-values \\
\hline SCHEDULE & 0.58 & 10.68 & 0.14 & 4.64 & 0.59 & 5.71 & 0.41 & 11.08 & 2.03 & 19.39 \\
\hline PRICE & -0.45 & -7.80 & -0.08 & -2.28 & -3.15 & -8.48 & -1.83 & -23.85 & -0.86 & -16.04 \\
\hline FLEXIBLE & 0.73 & 15.09 & 0.44 & 15.66 & 0.75 & 5.94 & 0.42 & 13.02 & 0.79 & 16.55 \\
\hline FFLYER & 0.43 & 9.92 & 0.56 & 16.66 & 2.37 & 5.75 & 0.24 & 5.42 & 0.52 & 11.81 \\
\hline PUNCTUAL & 2.00 & 15.25 & 0.37 & 10.25 & 0.85 & 7.13 & 0.72 & 16.75 & 0.72 & 15.43 \\
\hline CATERING & 0.27 & 6.52 & 0.29 & 11.95 & 0.23 & 2.42 & 0.21 & 5.85 & 0.23 & 6.50 \\
\hline GROUND & 0.17 & 4.47 & 0.14 & 6.16 & 0.27 & 4.58 & 0.14 & 5.59 & 0.23 & 6.58 \\
\hline SCHEDULE ${ }^{*}$ PRICE & -0.02 & $-0.47 n s$ & -0.03 & $-1.49 n s$ & 0.06 & $1.03 n s$ & -0.05 & -1.97 & 0.03 & $0.63 n s$ \\
\hline CATERING*PRICE & -0.03 & $-0.84 n s$ & 0.03 & $1.39 n s$ & 0.09 & 2.31 & 0.01 & $0.62 n s$ & 0.06 & 1.97 \\
\hline CONST & 0.07 & $1.42 n s$ & 0.06 & 2.18 & 0.12 & $1.74 n s$ & 0.03 & $0.92 n s$ & 0.04 & $1.30 n s$ \\
\hline Number of respondents & & 1108 & & 1105 & & 551 & & 1925 & & 1140 \\
\hline LL & \multicolumn{10}{|c|}{-21324.87} \\
\hline$\rho$ & \multicolumn{10}{|l|}{0.33} \\
\hline $\mathrm{BIC}$ & \multicolumn{10}{|c|}{43229.28} \\
\hline CAIC & \multicolumn{10}{|c|}{43229.28} \\
\hline \multicolumn{11}{|c|}{ Bold: first three parameter estimates with highest $t$-values } \\
\hline
\end{tabular}

Table 3 presents the segment-level partworth functions. T-values of partworth estimation parameters indicate the impact of corresponding features on choice probabilities and therefore the relevance of the feature for a purchase decision (Guadagni and Little, 1983). Based on statistical as well as contextual considerations, we can describe the within-class structure of the observations along five segments and interpret it from an airline's marketing perspective as follows:

- Punctuality, flexibility and schedule are the most important features for choices in the first segment. Thus, we label this segment "Efficiency/Punctuality". 
Consumers in this segment account for about $20 \%$ of the observed sample. This shows a considerable market potential for airlines. Companies who target this customer group should extend their strategic considerations also to the careful choice of appropriate airports. Externally induced effects and tendencies such as crowding and delays because of a growing demand combined with growing regulatory concerns can cause such customers to switch to an airline offering reliable schedules from different points of departure and/or arrival

- In the second segment, the most relevant features are benefits from FFP: catering and flexibility. The product features can be subsumed as "Comfort". Price sensitivity is lowest in this segment, making it an attractive one as well. Differentiation may be achieved by offering individualized services and bonuses. In particular, innovative measures of ground-level services should be considered, as the current offerings do not seem to be appraised even by this group. Furthermore, cost-saving potential may be realized by making compromises with respect to scheduling.

- Segment three represents the most price-sensitive customers and is labeled accordingly "Price". The overall lowest t-values of the utility estimates indicate especially high within-group preference heterogeneity. Customers in this segment agree mainly on price, although they also concur on punctuality. This indicates a more rational decision-making process, whereby personal benefits are of minor importance and are randomly sought. Interestingly, a significant interaction between catering and price can be observed: The price-conscious consumers get even more price-sensitive if they are not offered meal service. This indicates a potential price trap especially for low-cost carriers: the less 
comfort is given on-flight, the higher the commodification/commoditization, likely bringing with it a deterioration of customer retention.

- Customer preferences in the fourth segment are characterized by a mixture of price sensitivity and performance-related flight attributes. This simultaneous orientation on price and performance thus determines the name of the segment "Price/Performance". The overall highest t-values of utility estimates show high homogeneity of preference functions within this segment. This allows for managerial recommendations based on willingness-to-pay estimates. Schedule matters about as much as flexibility, whereas punctuality is of higher importance. In case of excessively long delays, airlines should thus strive for a high flight frequency. Consumers even honor this by a higher willingness-topay (interaction effect between schedule and price). Overall, this ought to be said against smaller airlines at larger hubs and for market concentration.

- Segment five may be characterized as "Catch all/Flexibility". This segment's preferences are broadly balanced across product features. The high t-values indicate a low heterogeneity within the segment. Thus, we assume this segment to contain those customers who perform informed as well as extensive tradeoffs between various, both utilitarian as well as hedonic product attributes. This segment may be hard to address, as everything is being sought for. A simultaneous optimization of product features would be appropriate to ensure a balanced satisfaction of customers in this segment. Nevertheless, it has to be checked against the backdrop of an airlines operational cost structure, whether customers in this segment should be addressed by a tailored product offering strategy at all. 


\section{$5 \quad$ Substantiation of Segments}

\subsection{Profiling of segments}

In deriving the five-segment solution, we have gained information about the product features that matter to the identified segments. However, we still do not have information about the consistency of the segments in terms of the composition of each derived segment's "membership base". Who are the customers assigned to each segment during latent class modeling and what are their attitudes and habits? While the latent class estimation makes use of latent utilities as a segmentation basis, it does not automatically deliver information about the composition of the segments. However, this is what marketing managers need: "fencing" mechanisms for addressing and reaching target customers in segments.

In order to gain segment-based insights we first assign customers to segments according to the highest assertion probabilities. Second, we generate segment-based demographic and attitudinal profiles by using additional information provided by variables included in the FFP survey beyond the choice based conjoint data. Table 4 displays the relative frequencies of socio-demographic and attitudinal variables in the respective segments compared to those of the entire sample. 
Table 4: Deviances of frequencies compared to total sample

\begin{tabular}{|c|c|c|c|c|c|c|c|c|c|c|}
\hline \multirow[t]{2}{*}{ SEGMENTS } & \multicolumn{2}{|c|}{$\begin{array}{l}\text { Seg. } 1 \\
\text { "Efficiency/Punctuality" }\end{array}$} & \multicolumn{2}{|c|}{$\begin{array}{l}\text { Seg. } 2 \\
\text { "Comfort" }\end{array}$} & \multicolumn{2}{|c|}{ Seg. 3 "Price" } & \multicolumn{2}{|c|}{$\begin{array}{l}\text { Seg. } 4 \\
\text { "Price/ } \\
\text { Performance“ }\end{array}$} & \multicolumn{2}{|c|}{$\begin{array}{l}\text { Seg. } 5 \text { "Catch } \\
\text { all/Flexibxibility" }\end{array}$} \\
\hline & $(\%)$ & t-value & $(\%)$ & t-value & $(\%)$ & t-value & $(\%)$ & t-value & $(\%)$ & t-value \\
\hline \multicolumn{11}{|l|}{ DECISION MAKING BUSINESS } \\
\hline yourself & $-2,0$ & $-1,5$ & 0,0 & 0,0 & 1,0 & 0,6 & 1,0 & 0,9 & $-1,0$ & $-0,8$ \\
\hline co travel office & 2,0 & $2,0^{*}$ & 1,0 & 1,0 & 2,4 & 1,8 & $-0,9$ & $-1,1$ & 1,1 & 1,1 \\
\hline external travel office & $-1,0$ & $-1,4$ & 4,0 & $5,2^{*}$ & $-1,9$ & $-2,0^{*}$ & $-0,5$ & $-1,0$ & $-0,1$ & $-0,1$ \\
\hline employee & 1,0 & 1,3 & $-1,0$ & $-1,3$ & $-0,1$ & $-0,1$ & $-0,6$ & $-0,9$ & $-0,8$ & $-1,1$ \\
\hline \multicolumn{11}{|l|}{ BOOKING OF BUSINESS TRIPS } \\
\hline yourself & $-7,0$ & $-4,9^{*}$ & $-4,1$ & $-2,8^{*}$ & 7,1 & $3,6^{*}$ & 12,0 & $10,0^{*}$ & $-4,6$ & $-3,2^{*}$ \\
\hline co travel office & 3,0 & $2,1^{*}$ & 3,1 & $2,2^{*}$ & $-2,9$ & $-1,5$ & $-5,0$ & $-4,4^{*}$ & 0,2 & 0,2 \\
\hline external travel agent & 1,0 & 0,7 & $-1,1$ & $-0,7$ & $-5,9$ & $-3,0^{*}$ & $-6,0$ & $-5,2^{*}$ & 3,1 & $2,1^{*}$ \\
\hline employee & 2,0 & 1,5 & 0,8 & 0,6 & 0,3 & 0,2 & $-3,0$ & $-2,9^{*}$ & 0,1 & 0,1 \\
\hline \multicolumn{11}{|l|}{ DECISION MAKING LEISURE } \\
\hline yourself & 0,0 & 0,0 & $-3,9$ & $-5,2^{*}$ & $-1,1$ & $-1,2$ & $-1,1$ & $-1,97^{*}$ & 1,0 & 1,4 \\
\hline co travel office & 0,0 & 0,0 & 1,3 & $2,3^{*}$ & 0,8 & 1,1 & 0,9 & $2,0^{*}$ & $-1,0$ & $-1,9^{*}$ \\
\hline external travel office & $-1,3$ & $-2,8^{*}$ & 2,0 & $3,8^{*}$ & 0,0 & 0,0 & $-0,1$ & $-0,2$ & $-1,1$ & $-2,4^{*}$ \\
\hline employee & 0,0 & 0,0 & 0,3 & $4,4^{*}$ & 0,0 & & 0,0 & & 0,8 & $6,8^{*}$ \\
\hline \multicolumn{11}{|l|}{ BOOKING OF LEISURE TRIPS } \\
\hline yourself & $-1,0$ & $-1,3$ & $-1,6$ & $-2,0^{*}$ & $-0,5$ & $-0,5$ & $-11,9$ & $-15,9^{*}$ & $-1,2$ & $-1,6$ \\
\hline co travel office & 2,0 & $3,4^{*}$ & 1,6 & $2,8^{*}$ & 1,6 & $2,1^{*}$ & 5,7 & $10,5^{*}$ & 2,6 & $4,5^{\star}$ \\
\hline external travel office & 0,0 & 0,0 & 1,0 & $2,1^{*}$ & $-0,1$ & $-0,1$ & 1,2 & $3,1^{*}$ & $-0,4$ & $-0,9$ \\
\hline employee & 0,0 & & 0,0 & & 0,0 & & 5,3 & $17,7^{*}$ & 0,0 & \\
\hline \multicolumn{11}{|l|}{ MODE OF BOOKING } \\
\hline carrier call center co & 2,2 & $2,8^{*}$ & 3,7 & $4,6^{*}$ & $-2,0$ & $-2,0^{*}$ & $-1,4$ & $-2,3^{*}$ & 0,0 & 0,0 \\
\hline online carrier website & $-9,0$ & $-6,3^{*}$ & $-10,1$ & $-7,1^{*}$ & 4,5 & $2,4^{*}$ & 5,3 & $4,8^{*}$ & $-0,2$ & $-0,1$ \\
\hline tel/face to face (ftf) & 1,1 & 1,6 & 2,5 & $3,8^{*}$ & $-1,0$ & $-1,2$ & $-0,3$ & $-0,6$ & $-2,3$ & $-3,8^{*}$ \\
\hline tel/ftf travel agent & 3,4 & $3,4^{*}$ & 5,1 & $5,1^{*}$ & 0,3 & 0,2 & $-3,5$ & $-4,7^{*}$ & 1,3 & 1,4 \\
\hline online travel portal & 2,4 & $3,8^{*}$ & $-1,4$ & $-2,4^{*}$ & $-1,8$ & $-2,3^{*}$ & 0,4 & 0,7 & 0,1 & 0,2 \\
\hline
\end{tabular}


continued...

\begin{tabular}{|c|c|c|c|c|c|c|c|c|c|c|}
\hline \multicolumn{11}{|l|}{ FLYING FREQUENCY } \\
\hline several times/week & 1,4 & $2,6^{*}$ & 0,1 & 0,1 & $-0,9$ & $-1,4$ & $-1,1$ & $-2,7^{*}$ & 0,6 & 1,1 \\
\hline several times/month & 6,2 & $4,2^{*}$ & 2,8 & 1,9 & $-7,3$ & $-3,7^{*}$ & $-6,3$ & $-5,4^{*}$ & 5,3 & $3,6^{*}$ \\
\hline 1/month & 2,0 & 1,4 & $-1,4$ & $-1,0$ & $-4,6$ & $-2,4^{*}$ & $-1,2$ & $-1,1$ & 3,9 & $2,8^{*}$ \\
\hline $1 / 3$ months & $-4,5$ & $-3,0^{*}$ & $-0,6$ & $-0,4$ & 6,8 & $3,3^{*}$ & 3,6 & $2,9^{*}$ & $-4,5$ & $-3,0^{*}$ \\
\hline $1 / 6$ months & $-3,6$ & $-3,4^{*}$ & $-0,8$ & $-0,8$ & 4,8 & $3,2^{*}$ & 4,0 & $4,5^{\star}$ & $-4,4$ & $-4,2^{*}$ \\
\hline 1/year & $-1,4$ & $-3,0^{*}$ & 0,1 & 0,2 & 1,2 & 1,7 & 0,9 & $2,1^{*}$ & $-1,1$ & $-2,3^{*}$ \\
\hline \multicolumn{11}{|l|}{ GENDER } \\
\hline female & $-3,7$ & $-2,9^{*}$ & $-3,9$ & $-3,0^{*}$ & 2,6 & 1,5 & 4,5 & $4,2^{*}$ & $-1,6$ & $-1,3$ \\
\hline \multicolumn{11}{|l|}{ AGE } \\
\hline $15-24$ & $-1,5$ & $-3,0^{*}$ & $-0,5$ & $-0,9$ & 0,5 & 0,6 & 1,2 & $2,8^{*}$ & $-0,4$ & $-0,9$ \\
\hline $25-39$ & 0,4 & 0,2 & $-7,0$ & $-4,4$ & 0,8 & 0,4 & 2,5 & 1,9 & 1,8 & 1,2 \\
\hline $40-49$ & 1,4 & 0,9 & 0,8 & 0,5 & $-3,6$ & \begin{tabular}{|l|}
$-1,8$ \\
\end{tabular} & $-2,3$ & \begin{tabular}{|c|}
$-1,9$ \\
\end{tabular} & 3,4 & $2,3^{*}$ \\
\hline $50-64$ & $-0,1$ & 0,0 & 5,8 & $4,0^{*}$ & 0,7 & 0,4 & $-1,9$ & $-1,7$ & $-2,7$ & $-1,9$ \\
\hline over 64 & $-0,3$ & $-0,4$ & 0,9 & 1,5 & 1,6 & $2,0^{*}$ & 0,6 & 1,2 & $-2,1$ & $-3,9^{*}$ \\
\hline \multicolumn{11}{|c|}{ EDUCATIONAL LEVEL } \\
\hline University & 5,6 & $3,5^{*}$ & $-5,5$ & $-3,4^{*}$ & $-4,7$ & $-2,1^{*}$ & $-1,4$ & $-1,1$ & 4,6 & $2,9^{*}$ \\
\hline High school & $-1,5$ & $-1,5$ & 1,3 & 1,3 & 2,1 & 1,5 & 0,7 & 0,8 & $-1,5$ & $-1,5$ \\
\hline Apprenticeship & $-3,2$ & $-2,2^{*}$ & 4,0 & $2,7^{*}$ & 2,4 & 1,2 & 0,6 & 0,5 & $-2,8$ & $-1,9$ \\
\hline prel. job-instructions & $-0,2$ & $-1,4$ & 0,0 & 0,0 & 0,2 & 1,0 & 0,0 & 0,3 & 0,4 & $2,3^{*}$ \\
\hline \multicolumn{11}{|l|}{ PROFESSION } \\
\hline Entrepreneur & $-1,4$ & $-1,2$ & 0,4 & 0,4 & 1,4 & 0,9 & 2,2 & $2,3^{*}$ & $-3,2$ & $-2,8^{*}$ \\
\hline Leadership & 8,3 & $5,1^{*}$ & 4,4 & $2,7^{*}$ & $-9,9$ & $-4,5^{*}$ & $-7,4$ & $-5,7^{*}$ & 5,2 & $3,3^{*}$ \\
\hline No Leadership & $-2,1$ & $-1,5$ & $-4,3$ & $-3,1^{*}$ & 4,7 & $2,5^{*}$ & 1,9 & 1,7 & 0,9 & 0,7 \\
\hline Training & $-1,7$ & $-4,4^{*}$ & $-0,5$ & $-1,3$ & 0,6 & 1,1 & 1,2 & $3,2^{*}$ & $-0,7$ & $-1,6$ \\
\hline Houswife & $-1,2$ & $-3,7^{*}$ & $-0,4$ & $-1,2$ & $-0,3$ & $-0,6$ & 1,3 & $3,9^{*}$ & $-0,9$ & $-2,6^{*}$ \\
\hline Retired & $-0,7$ & $-1,4$ & 0,5 & 1,0 & 2,9 & $3,9^{*}$ & 0,7 & 1,6 & $-1,6$ & $-3,1^{*}$ \\
\hline
\end{tabular}

Based on these results, the following segment-based typologies can be recognized:

Customers belonging to segment "Efficiency/Punctuality" are more than frequent flyers.

These customers virtually "live" in airplanes. They even fly several times per week and 
are predominantly male. They consequently outsource both the decision and the booking of flights for business reasons. This behavior changes when it comes to leisure trips. Here, they decide themselves as much as the other segments' customers do. The booking of leisure trips is then left to company travel offices. Due to the unforeseeable schedule of these customers, the efficiency/flexibility seekers are forced to value flexibility and punctuality, no matter what the price of the offer is. Their flights requirements are on short notice and it would be too time-consuming and would add to the transaction costs if the persons making the booking were frequenting one carriers' website after the other. This is why the company-internal travel offices, besides relying on carriers' telephone call centers and calling or meeting independent travel agents, also rely on general online travel portals. We find a similarly high percentage of customers with university degrees working in leadership positions, probably senior management positions. In sum, these characteristics are consistent with the segment-specific preference focus on efficiencyrelated features such as punctuality, flexibility and schedule and the relatively low price sensitivity.

The second segment, whose focus is on "Comfort", consists of elderly customers also working in high-ranking positions, i.e. probably middle-to-senior management. They also comprise a relatively high proportion of employees with apprenticeship as their highest educational degree. Hence, these employees have attained their hierarchical level due to a longer career track than in the "efficiency/punctuality" segment. These customers typically fly several times per month. Choice decisions and booking of flights for both business and leisure trips are mostly made by external travel agents. While being frequent flyers, their travel frequency still allows them to seek personal interaction when booking, giving either face-to-face or telephone instructions. They do not use the Internet as a 
booking medium, neither in the form of online carrier nor general online travel portals. The second segment's population is also composed of an above-average proportion of males. In sum, the characteristics of the segment, e.g. the frequent but foreseeable travel occurrences, the comparably higher age, and the conclusion from education and profession that these customers had to earn their status, lead us to conclude that they show more involvement than the efficiency/flexibility segment. This explains the high partworths for the comfort-oriented feature and the fact that price is the most irrelevant factor in choice decisions.

Customers belonging to the "Price segment seem to be in the lower-to-middle echelons of management, i.e. they have no leadership responsibilities. They do not decide on the choice of business flights significantly more than respondents assigned to other segments. Single bookings, however, are made after a decision is made by the company travel agent. Because of the travel frequency of 2-4 times a year, it is plausible to assume that the companies follow internal strategy restrictions in order to minimize costs. The trip frequency allows early planning of trips and therefore carriers' websites to be used as a cost efficient mode of booking more often than in other segments, with the exception of segment four. The segment's composition is not as male-dominated as the first two segments, rather evenly distributed among the age categories (except for the fact it contains more respondents over 64 years of age), and characterized by solid educational background, i.e. apprenticeship and high school but not university level. In sum, these characteristics are consistent with the narrow, segment-specific preference with a focus on price. Schedule (flight plan), frequent flyer bonuses, catering, and efficient ground services are not relevant decision drivers. 
Customers belonging to the "Price/Performance" segment base their choice decisions on a mixture of price and quality. Price is still important, but efficiency-related features, such as punctuality, flexibility and schedule become more relevant than in segment three. This focus on price/performance is in keeping with the comparably high rate of entrepreneurs in this segment. Since entrepreneurs have to pay the costs of their business flights themselves, they are more price-sensitive. While there is no recognizable pattern concerning decision making for business flights, there is a tendency for the segment's members to leave the decision to those who know about the best price/performance ratios, i.e. corporate travel agents. When it comes to booking flights, they book business flights themselves, while leisure flight booking is left to the company's travel agent, employees, or external travel agents. Besides entrepreneurs, the segment includes lower-to-middle management employees who value price/performance ratio more than solely price, compared to their lower-middle-management counterparts in segment three. Furthermore, this segment is the youngest segment identified and encompasses significantly more women (housewives) and trainees. This may help to explain the high relevance of price for choice decisions as well.

Customers belonging to the "Catch all/Flexibility" segment are managers in important positions, flying relatively often (several times a month) and outsourcing the decision and the booking processes. Presumably caused by their stronger decision power due to their hierarchical level and age (relatively more between 40 and 49) they have individualized preferences. This is indicated by the highly differentiated preference pattern in this segment: partworths are generally more balanced across product features than in other segments. A Schedule and flexibility are slightly more relevant, presumably due to the high flight frequency and high degree of decision autonomy. The size of the segment, its 
sociodemographic structure as well as the travel behavior, make this segment an interesting candidate for airlines. However, the above-outlined preference structure makes this segment difficult to address, as various and costly product features need to be addressed simultaneously. Furthermore, direct communication with these customers is not easy to achieve, as they overproportionally book even leisure trips through company travel agents and avoid face-to-face bookings. Thus, it would appear that a sophisticated approach to consumer interaction is needed, e.g. by implementing database-driven customer relationship management.

\subsection{Cross-Validation of Segmentation Approach}

Comparing the a priori classification with the latent class model shows that the latter delivers a more finely grained segmentation of customer preferences. Beyond the counting of segments, we wanted to investigate whether and how strong an overlap exists between the solutions offered by the two segmenting approaches. We are interested in discovering existing systematic dependencies or independencies between the resulting customer structures in order to further investigate the preferences in our sample. We assume systematic dependencies or overlap between both classification structures. This assumption is underlined by unequal frequencies of the contingency table of customer allocation in latent vs. a priori classes. Using a non-parametrical $\chi 2$-test we check for systematic dependencies between categories of both classification approaches. The test statistics (527) is greater than the critical value (30) for df 19 and 5\% error probability and does not support the null hypothesis of independence between both segmenting solutions. Based on this result, we analyze further, whether customers flying for a specific reason in a specified class state similar preference structures. This is tested by comparing 
the marginal quota of a-priori classes in each latent segment with those in the whole sample. The results are given in Table 5 .

Table 5: Marginal distribution of latent classes (t-values in parenthesis)

\begin{tabular}{|c|c|c|c|c|c|}
\hline A-priori & $\begin{array}{l}\text { Business } \\
\text { Class/ } \\
\text { Business } \\
\text { Reason }\end{array}$ & $\begin{array}{l}\text { Business } \\
\text { Class/ } \\
\text { Leisure } \\
\text { Reason }\end{array}$ & $\begin{array}{l}\text { Economy } \\
\text { Class / } \\
\text { Business } \\
\text { Reason }\end{array}$ & $\begin{array}{l}\text { Economy } \\
\text { Class / } \\
\text { Leisure } \\
\text { Reason }\end{array}$ & SAMPLE \\
\hline Seg. 1: Efficiency/Punctuality & $\begin{array}{c}0.69 \\
\left(4.64^{* \star \star}\right)\end{array}$ & $\begin{array}{c}0.16 \\
\left(-3.71^{* * *}\right)\end{array}$ & $\begin{array}{l}0.14 \\
(0.83)\end{array}$ & $\begin{array}{c}0.01 \\
(-0.10)\end{array}$ & 0.19 \\
\hline Seg. 2: Comfort & $\begin{array}{c}0.55 \\
(-0.63)\end{array}$ & $\begin{array}{c}0.25 \\
\left(-1.78^{\star \star}\right)\end{array}$ & $\begin{array}{c}0.17 \\
\left(1.56^{\star \star \star}\right)\end{array}$ & $\begin{array}{l}0.02 \\
(0.27)\end{array}$ & 0.19 \\
\hline Seg. 3: Price & $\begin{array}{c}0.46 \\
\left(-2.67^{* * *}\right)\end{array}$ & $\begin{array}{c}0.46 \\
\left(2.97^{* * \star}\right)\end{array}$ & $\begin{array}{c}0.07 \\
(-0.64)\end{array}$ & $\begin{array}{l}0.02 \\
(0.08)\end{array}$ & 0.09 \\
\hline Seg. 4: Price/Performance & $\begin{array}{c}0.49 \\
\left(-3.62^{* * *}\right)\end{array}$ & $\begin{array}{c}0.46 \\
\left(5.56^{\star * *}\right)\end{array}$ & $\begin{array}{c}0.05 \\
\left(-1.68^{\star *}\right)\end{array}$ & $\begin{array}{c}0.01 \\
(-0.12)\end{array}$ & 0.33 \\
\hline Seg. 5: Catch all/Flexibility & $\begin{array}{c}0.65 \\
\left(3.77^{\star \star \star}\right)\end{array}$ & $\begin{array}{c}0.21 \\
\left(-2.80^{* * *}\right)\end{array}$ & $\begin{array}{l}0.13 \\
(0.63)\end{array}$ & $\begin{array}{c}0.01 \\
(-0.09)\end{array}$ & 0.20 \\
\hline & & & & & $\begin{aligned} * * & \alpha=0.01 \\
* & \alpha=0.05 \\
* & : \alpha=0.1\end{aligned}$ \\
\hline
\end{tabular}

The four combinations of travel reason and class flown relate to our latent classes as follows:

- Customers traveling for business in business-class are overrepresented in the first ("Efficiency/Punctuality”) and fifth ("Catch all/Flexibility”) segments. These results are consistent with the derived segment profiles, i.e. high education and senior hierarchical level, high flight frequency, and the outsourcing of decision and booking processes. 
- Passengers flying for business in economy-class are mainly found in the third ("price") and fourth ("price/performance") segments. This underlines the heterogeneous nature of this segment: besides managers of lower-middle management levels, we find younger entrepreneurs. These two customer segments are price-oriented as has been discussed in the segments' descriptions above.

- Customers flying business-class for leisure are presumably wealthy. This is confirmed by the results, since this segment is overrepresented in the comfortoriented, second latent segment.

- Customers flying for leisure in economy class are distributed evenly over the latent classes. An obvious reason for their diffuse distribution among the latent classes can be seen in the small size of this customer group, i.e. this class consists of only 68 customers.

The comparison of both classification approaches bears two main implications. First it validates the solution derived by the application of latent class segmentation. Even after comparing them to the a priori segmentation 'solution', the identified customer segments make intuitive sense and the preference patterns correspond to respective sociodemographic profiles. Second, by combining the two information sources about airline customer segmentation, we bridge the gap between latent and a priori segmentation logics. The detailed segment profiles can be used as fencing mechanisms for addressing each of the identified customer segments also within the traditional a-priori segments. This is a valuable management instrument for the development of sustainable customeroriented product policies matching so far latent preferences in so far taken for granted customer segments. 


\section{Discussion and Managerial Impacts}

Based on our results we conclude that the actual segmentation criterion applied by airlines, i.e. transportation class flown does not adequately mirror the heterogeneity in customers' preference patterns. We identify five segments according to preferences for different product features and profile the segments using additional attitudinal and sociodemographic variables. The derived profiles indicate that the dominant marketing strategy of airlines based on price for economy and flexibility for business travelers is not discriminatory enough to cover the broad preference-spectrum. The segment profiles reveal three potential avenues for product specialization: comfort, efficiency, and priceoriented offerings. Comfort products address managers in hierarchically high employment positions flying for business reasons in business class, as well as well-off leisure travelers. Price-oriented products are of interest to a wider range of customers: This offering is targeted at entrepreneurs, middle-ranking, younger managers and retirees. Efficiency is relevant mainly for business travelers flying every other day for business reasons, mainly in very high-ranking positions.

The marketing strategies for the customized product packages should be aligned to the attitudes and socio-demographic profiles leading to a specific set of preferences in the respective customer segments. But even within these three basic categories of offerings, there is still considerable room for differentiation in order to arrive at more fine-grained segments .For instance, in our study "efficiency" consists of the three features punctuality, schedule and flexibility. Hence, different advertising campaigns can be implemented which address these different features individually. Improving punctuality, 
with a focus on reduction in travel times (Jiang and Morikawa, 2004) could address a different sub-segment, than would a campaign focusing on flexibility. However, bcause punctuality is the most important feature for customers of segments one and three, these customers can be best addressed with product offerings fostering a high degree of punctuality. Flexibility of tickets or schedule of flights would change to a lesser degree these customers' propensity to buy a flight.

These results indicate the importance of product/service innovation for future market success of airlines: A current misfit of product offerings with price-quality preferences of both business- as well as leisure-class travelers stresses the need to refocus product offerings. A holistic view on market development is needed, because strategic measures (e.g. airport selection) interact with operative measures (punctuality). Finally, a routespecific optimization of product features seems feasible, given that demand structure may be geographically different.

Addressing the needs of a larger market segment or a smaller market niche may avoid the trap of commoditization and increase willingness to pay. The study showed that utilitarian as well as hedonic product features may contribute to achieving such a unique selling proposition. The 'fine-tuning' of product features needs to take the cost structure of airlines into account. This holds especially, as different technical solutions may lead to similar customer benefits. Since customers trade off the various product attributes such as schedule, flexibility and punctuality, different airlines may come up with different but equally acceptable product offerings based on their strategic setting.

While we addressed the demand issues from the marketing viewpoint of single airline companies, our findings have policy implications as well: Addressing the revealed 
preference patterns might have an impact on the overall market structure. Given that punctuality matters for most segments to a large extent, crowding and delays may continue to shift the overall demand to regional airports with less congestion. Even in the case of unrestricted price competition, an imbalance in market power is likely to remain, as scheduling mixed with flexibility constitutes inherent advantages of established, large carriers. Anti-trust enforcements should thus place heavy burdens on product-quality related features such as code-sharing or other flexibility-enhancing product components. Overall, econometric models should avoid focusing on price alone but should model revealed preference heterogeneity so as to better predict both future demand size as well as demand structure.

Summarizing, we have shown the need for a stronger differentiation of product offerings as customized packages for adequate, i.e. responsive customer segments. Second, we specify an alternative segmentation method by combining preference patterns for product features with noticeable attitudinal and individual variables and derive managerial implications. However, since our results probably contain context-specific biases, i.e. European short-haul passengers and FFP members of one specific airline were questioned, there remain doubts as to the generalization of our findings. Thus, for the development of new products for specific segments, further in-depth analyses of perceptions and of the impact of context on choice behavior are necessary. 


\section{Appendix}

Table A. 1: Logit estimation of the four a-priori segments according to class flown and travel reason

\begin{tabular}{|c|c|c|c|c|c|c|c|c|}
\hline & \multicolumn{2}{|l|}{ 1. $\mathrm{BC} / \mathrm{BR}$} & \multicolumn{2}{|l|}{ 2. $\mathrm{BC} / \mathrm{LR}$} & \multicolumn{2}{|l|}{ 3: EC/ BR } & \multicolumn{2}{|l|}{ 4: EC/LR } \\
\hline & Parameters & t-values & Parameters & t-values & Parameters & t-values & Parameters & t-values \\
\hline SCHEDULE & 0,51 & 54,69 & 0,34 & 25,92 & 0,50 & 21,30 & 0,10 & 2,24 \\
\hline PRICE & $-0,62$ & $-54,10$ & $-1,01$ & $-54,41$ & $-0,25$ & $-12,31$ & $-0,32$ & $-5,80$ \\
\hline FLEXIBILITY & 0,43 & 52,89 & 0,32 & 32,82 & 0,57 & 24,36 & 0,33 & 4,94 \\
\hline FFLYER & 0,40 & 45,99 & 0,44 & 36,10 & 0,43 & 21,35 & 0,36 & 6,16 \\
\hline PUNCTUALITY & 0,67 & 59,87 & 0,47 & 39,39 & 0,65 & 30,65 & 0,30 & 6,08 \\
\hline CATERING & 0,21 & 23,42 & 0,12 & 11,11 & 0,27 & 14,16 & 0,19 & 3,37 \\
\hline GROUND & 0,14 & 16,00 & 0,11 & 9,25 & 0,12 & 5,71 & 0,04 & $0,69^{*}$ \\
\hline SCHEDULE*PRICE & $-0,02$ & $-1,63^{*}$ & $-0,02$ & $-1,25^{*}$ & $-0,01$ & $-0,52^{*}$ & $-0,03$ & $-0,70^{*}$ \\
\hline CATERING*PR & 0,02 & 2,36 & 0,02 & $1,87^{*}$ & $-0,02$ & $-1,01^{*}$ & 0,04 & $0,69^{*}$ \\
\hline CONST & 0,02 & $1,52^{*}$ & 0,08 & 4,20 & $-0,01$ & $-0,32^{*}$ & $-0,01$ & $-0,13^{*}$ \\
\hline Likelihood & $-12619,07$ & & $-6819,35$ & & $-2478,88$ & & $-321,26$ & \\
\hline LL & 0,30 & & 0,31 & & 0,27 & & 0,13 & \\
\hline$\rho$ & 25339,76 & & 13734,43 & & 5042,79 & & 705,33 & \\
\hline $\mathrm{BIC}$ & 25339,76 & & 13734,43 & & 5042,79 & & 705,35 & \\
\hline CAIC & 25898,00 & & 14363,00 & & 4924,00 & & 534,00 & \\
\hline Number of respondents & 3311,00 & & 1834,00 & & 1834,00 & & 68,00 & \\
\hline
\end{tabular}

Table A. 2: Goodness-of-fit measures for different numbers of segments

\begin{tabular}{|l|l|l|l|l|l|}
\hline \hline Index & 2 & 3 & 4 & 5 & 6 \\
\hline \hline LL & -22055.05 & -21657.77 & -21538.80 & -21324.87 & -22055.05 \\
\hline$\rho$ & 0.31 & 0.32 & 0.32 & 0.33 & 0.31 \\
\hline BIC & 44335.48 & 43658.97 & 43539.08 & 43229.28 & 44807.70 \\
\hline CAIC & 44335.48 & 43658.97 & 43539.08 & 43229.28 & 44807.70 \\
\hline \hline
\end{tabular}




\section{References}

Abramson, C., Andrews, R. L., Currim, I. S. \& Jones, M. (2000) Parameter bias from unobserved effects in the multinomial logit model of consumer choice. Journal of Marketing Research, 37, 410-426.

Alamdari, F. \& Mason, K. (2006) The future of airline distribution. Journal Of Air Transport Management, 12, 122-134.

Allenby, G., Fennell, G., Bemmaor, A., Bhargava, V., Christen, F., Dawley, J., Dickson, P., Edwards, Y., Garratt, M., Ginter, J., Sawyer, A., Staelin, R. \& Yang, S. (2002) Market segmentation research: Beyond within and across group differences. Marketing Letters, 13, 233-243.

Anable, J. (2005) 'Complacent Car Addicts' or 'Aspiring Environmentalists'? Identifying travel behaviour segments using attitude theory. Transport Policy, 12, 65.

Anable, J. \& Gatersleben, B. (2005) All work and no play? The role of instrumental and affective factors in work and leisure journeys by different travel modes. Transportation Research Part A-Policy and Practice, 39, 163.

Chintagunta, P. K., Jain, D. C. \& Vilcassim, N. J. (1991) Investigating heterogeneity in brand preferences in logit-models for panel data. Journal of Marketing Research, 28, 417-428.

Desarbo, W. S. \& Jedidi, K. (1995) The spatial representation of heterogeneous consideration sets. Marketing Science, 14, 326-342.

Doganis, R. (2006) The Airline Business, London and New York, Routledge.

Guadagni, P. M. \& Little, J. D. C. (1983) A logit model of brand choice calibrated on scanner data. Marketing Science, 2, 203-239.

Gupta, S. \& Chintagunta, P. K. (1994) On using demographic-variables to determine segment membership in logit mixture-models. Journal of Marketing Research, 31, 128-136.

Haaijer, R., Wedel, M., Vriens, M. \& Wansbeek, T. (1998) Utility covariances and context effects in conjoint MNP models. Marketing Science, 17, 236.

Hensher, D., Louviere, J. \& Swait, J. (1999) Combining sources of preference data. Journal of Econometrics, 89, 197. 
Hensher, D. A. (1994) Stated preference analysis of travel choices - the state of practice. Transportation, 21, 107-133.

Inglanda, V., Rey, B., Rodríguez-Alvarez, A. \& Coto-Millan, P. (2006) Liberalisation and efficiency in international air transport. Transportation Research Part A, 40, 95-105.

Jiang, M. \& Morikawa, T. (2004) Theoretical analysis on the variation of value of travel time savings. Transportation Research Part A, 38, 551-571.

Johansson, M. V., Heldt, T. \& Johansson, P. (2006) The effects of attitudes and personality traits on mode choice. Transportation Research Part A-Policy And Practice, 40, 507-525.

Kamakura, W. A., Kim, B. D. \& Lee, J. (1996) Modeling preference and structural heterogeneity in consumer choice. Marketing Science, 15, 152-172.

Kamakura, W. A. \& Russell, G. J. (1989) A probabilistic choice model for marketsegmentation and elasticity structure. Journal of Marketing Research, 26, 379390.

Kim, J., Allenby, G. M. \& Rossi, P. E. (2002) Modeling consumer demand for variety. Marketing Science, 21, 229-250.

Lindstadt, H. \& Fauser, B. (2004) Separation or integration? Can network carriers create distinct business streams on one integrated production platform? Journal of Air Transport Management, 10, 23-31.

Louviere, J. (1988) Conjoint-Analysis modeling of stated preferences - a review of theory, methods, recent developments and external validity. Journal of Transport Economics and Policy, 22, 93-119.

Louviere, J. (2001) What if consumer experiments impact variances as well as means? Response variability as a behavioral phenomenon. Journal of Consumer Research, 28, 506.

Louviere, J., Hensher, D. \& Swait, J. (2000) Stated choice methods: Analysis and applications, Cambridge U.K., Cambridge University Press.

Mason, K. (2002) Future trends in business travel decision making. Journal of Air Transportation, 7, 47-69.

Mason, K. (2003) Cleared for take-off: structure and strategy in the low fare airline business. Journal of Air Transport Management, 9, 69-70. 
Mason, K. (2005) Observations of fundamental changes in the demand for aviation services. Journal of Air Transport Management, 11, 19-25.

Mcfadden, D. (1974) Conditional logit analysis of qualitative choice behaviour. IN ZAREMBKA, P. (Ed.) Frontiers in Econometrics. New York, Academic Press.

Morikawa, T. (1989) Incorporating stated preferences in travel demand analysis. Department of Civil Engineering M.I.T.

Palmer, R. A. \& Millier, P. (2004) Segmentation: Identification, intuition, and implementation. Industrial Marketing Management, 33, 779.

Swait, J. \& Louviere, J. (1993) The Role of the scale parameter in the estimation and comparison of multinomial logit-models. Journal of Marketing Research, 30, 305.

Swan, W. M. (2002) Airline demand distributions: passenger revenue management and spill. Transportation Research Part E-Logistics and Transportation Review, 38, 253-263.

Train, K. (2003) Discrete choice methods with simulation, Cambridge, Cambridge University Press.

Vermunt, J. K. \& Magidson, J. (2003) Latent class models for classification. Computational Statistics \& Data Analysis, 41, 531-537.

Wedel, M. \& Kamakura, W. A. (2000) Market segmentation conceptual and methodological foundations, Kluwer Academic Publishers.

Yankelovich, D. \& Meer, D. (2006) Rediscovering market segmentation. Harvard Business Review, 84, 122-131. 